\title{
THE ROLE OF E-LEADERSHIP IN RELATION TO IT CAPABILITIES AND DIGITAL TRANSFORMATION
}

\author{
Pascal Ravesteijn and Guido Ongena \\ HU University of Applied Sciences, Research Group Process Innovation and Information Systems \\ Heidelberglaan 15, Utrecht, The Netherlands
}

\begin{abstract}
In this research we examine the relationship between IT capability and digital transformation as well as the influence of digital leadership. A theoretical framework was developed to explain the effect of digital leadership. Subsequently this was tested using a survey of 127 respondents from firms across Western Europe. Consistent with our proposed model, this study finds that both IT capability and e-leadership positively influence digital transformation. However, there is mediating effect of e-leadership on the relation between IT capabilities and digital transformation.
\end{abstract}

\section{KEYWORDS}

Digital Leadership, IT Capability, Digital Transformation, e-Competence

\section{INTRODUCTION}

In today's digital society organizations can no longer ignore the range of new technologies that are available and can be used to improve or innovate its business (processes), products and/or services. Information technology capabilities can increase performance and be an enabler for innovation (Mithas, et al., 2011; Nwankpa \& Roumani, 2016). Furthermore, IT capabilities can also improve an organization's digital transformation readiness (Anand, Oriani, \& Vassolo, 2010; Nwankpa \& Roumani, 2016). However, to meet the challenges related to digital transformation employees need the right e-skills, and according to Hüsing et al. (2013) many European organizations don't have the correct set of competences available. This is specifically true at the management and leadership level of organizations. Organizations need digital leaders that can develop a digital strategy which enables the organization to digitally transform. While, a large amount of research is available on the topic of digital leadership and also on IT capabilities and digital transformation, empirical research that combines these three concepts is very limited. Therefore, the objective of this research is to determine the influence of e-leadership related competences on IT capabilities and digital transformation readiness.

\section{LITERATURE REVIEW}

In this section the topics of e-leadership (including e-competences and more specifically the European e-competence framework), IT capabilities, and digital transformation are discussed. For this review the following academic search engines were used: EBSCO, AIS library, HUGO (cross-database search engine of our university) and Google Scholar. Search terms and keywords included: leadership, innovation leadership, eleadership, e-leadership, digital leadership, digital transformation, digital competence, e-CF, European e-Competence Framework, information technology, IT, IT and organization, IT capabilities, technology capability, and IT leadership. Finally, the number of papers was narrowed to articles that had ten or more citations. 


\section{1 e-Leadership}

Definitions on e-leadership (also referred to as digital leadership) are commonly derived from definitions on leadership in general. Leadership is defined by Prentice (2004) as "the accomplishment of a goal through the direction of human assistants. The man who successfully marshals his human collaborators to achieve particular ends is a leader" (p.102). Based on this Avolio, Sosik, Kahai and Baker (2014) define e-leadership as "a social influence process embedded in both proximal and distal contexts mediated by AIT that can produce a change in attitudes, feelings, thinking, behaviour, and performance" (p.107), where AIT stands for Advanced Information Technology. Similarly, in the European eSkills VISION project Hüsing et al. (2013) propose that "e-leadership is the accomplishment of a goal that relies on ICT through the direction of human assistants and uses of ICT" (p.13).

What sets digital leaders apart from traditional leaders is that they aim for a digital strategy and a culture that enables the organization to digitally transform (Kane, et al., 2015). A strategic mindset is needed combined with the right behavior which leverages organization resources in order to create a meaningful and engaging culture to be able to turn investments in technologies and digital transformation into a competitive advantage (Sheninger, 2014; Westerman, et al., 2014b). However, Hüsing et al. (2013) found that many European organizations don't have the right set of competences which are needed to confront the challenges related to digital transformation. Both managers and employees need e-skills to "to initiate and guide innovation utilizing ICT" (Robinson, et al., 2015, p. 53) and therefore Robinson et al. propose the creation of a body of knowledge complemented with a set of competences that can be used to develop e-leadership curricula.

An important part of this body of knowledge is the European e-Competence Framework (e-CF). e-CF is a competency framework specifically developed for the IT domain. While there are other frameworks available for this domain (Plessius \& Ravesteyn, 2016), it is a standard which is set by the European Committee for Standardization (CEN, 2016) and therefore needs to be implemented by all EU member states. e-CF consists of 40 competences that can be rated using five proficiency levels ranging from associate to principal (e-CF, 2014). In addition to e-CF 30 ICT role profiles have been developed (CWA 16458-1, 2018) in order to increase transparency of the European ICT Skills landscape. These profiles provide a generic set of roles that are performed by ICT Professionals in (ICT) business processes. For this study the Digital Transformation Leader role profile is used to research the impact on IT capabilities and digital transformation readiness. The digital transformation leader is responsible for "the implementation of the digital transformation strategy of the organisation" (CWA 16458-1, 2018, pg. 33). The necessary e-competences that are related to this role are derived from e-CF and are as follows: business plan development, architecture design, innovating, business change management, and governance.

\subsection{IT Capabilities}

Different studies find that strong information technology capabilities increases organizational performance and can be an important enabler for growth and innovation (Mithas, et al., 2011; Nwankpa \& Roumani, 2016). Furthermore, Anand, Oriani, and Vassolo (2010) state that IT capabilities benefits digital transformation readiness. However, not everybody agrees with these findings. Coombs and Bierly (2006) state that researchers have not been able to consistently find empirical support for the relation between technological capability and organizational performance. According to Coombs and Bierly the reason for this is the multidimensionality of both technological capability and performance.

Bharadwaj (2000) defined IT capability as an organizations ability to organize and deploy IT-based resources in combination with other resources in the organization. Drnevich and Croson (2013) extended the notion of IT capability as 1) the firm's ability to mobilise and deploy IT based resources, "creating value in combination with other resources and capabilities, and 2) the firm specific IT enabled knowledge and routines that improve the value of non-IT resources" (p. 485). In many studies IT capability as a concept is further refined in different sub elements. Lu and Ramamurthy (2011) conceptualize IT capability as a latent construct reflected in three dimensions: IT infrastructure capability (the technological foundation), IT business spanning capability (business-IT strategic thinking and partnership), and IT proactive stance (opportunity orientation). In contrast, Chen and Tsou (2012) state that IT capability consist of four different resources: IT infrastructure, IT business experience, IT relationship resources, and IT human resources. 
Nwankpa and Roumani (2016) agree with Lu and Ramamurthy and use their IT capability to research the relationship with firm performance including whether digital transformation influences this relationship (see figure 1).

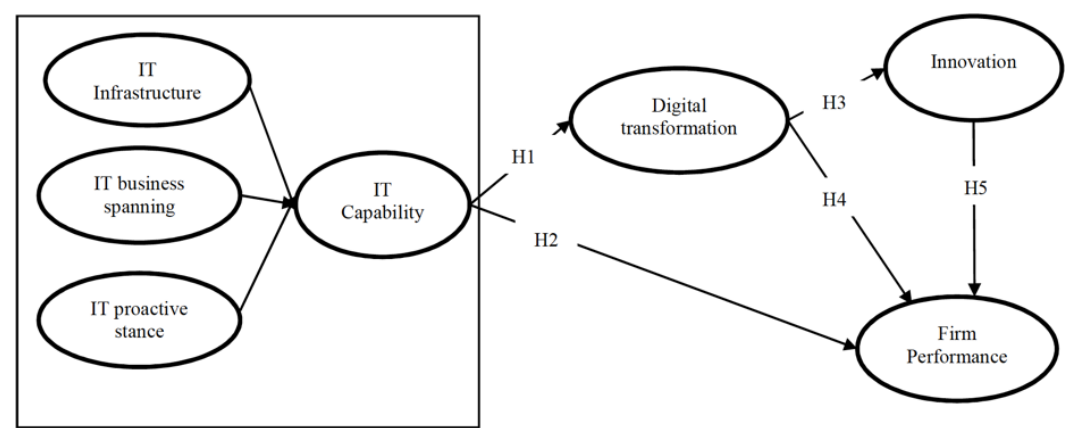

Figure 1. Research Model of Rwankpa \& Roumani (2016)

\subsection{Digital Transformation}

The fast majority of participants in a global survey of managers and executives that is conducted by MIT Sloan Management Review and Deloitte stated that digital technologies will disrupt their business (Kane, Phillips, Kiron \& Buckley, 2015). Despite this, only 44\% found that their organisation is adequately prepared to face the challenges caused by these new technologies (Kane et al., 2015). Therefore, organizations should strive for additional value creation in their products or services by using new technologies (Matt et al., 2015). Furthermore, customer facing processes should be as digital as possible. Such a transformation towards digital "constitutes a clear difference to process automation and optimization, since digital transformation strategies go beyond the process paradigm, and include changes to and implications for products, services, and business models as a whole" (Matt et al., 2015). According to Libert at al. (2016) digital transformation is not about technology, such as cloud computing big data or others, but about the change in the organization based on new technology in business models and processes.

Furthermore, digital transformation is not limited to an organization but can also be viewed from the perspective of societies, industries, networks, economies and individuals (Ismail, Khater \& Zaki, 2017). In this study however, the focus is on the organizational perspective. While there is a extensive amount of research on Digital Transformation, Henriette, Feki \& Boughzala (2015, p. 10) find that a "rigorous theoretical frame" is lacking. Kutzner, Schoormann \& Knackstedt (2018) concur by stating that a holistic structure for the digital transformation domain is still missing. However, according to Ismail et al. (2017) there is a general consent among scholars that digital transformation involves the application of technologies, in an effort to reach superior performance, related to three dimensions: external, internal and holistic (Ismail et al., 2017).

In this research we use the definition of digital transformation by Nwankpa \& Roumani (2016) as they have already studied this concept in relation to IT capabilities. Nwankpa \& Roumani define digital transformation as "the changes and transformations that are driven and built on a foundation of digital technologies" (p.4). Furthermore, in their research the digital transformation construct is specifically linked to technologies such as: big data, analytics, cloud, mobile and social media platform.

\subsection{Conceptual Model}

For this study a conceptual model is constructed (figure 2) consisting of three constructs. The IT capability and Digital Transformation constructs are based on the research by Nwankpa \& Roumani (2016) as depicted in figure 1. Furthermore, an e-leadership construct is added, this is developed in line with the e-competences that belong to the Digital Transformation Leader role (CWA 16458-1, 2018, pg. 33) as is described in section 2.1. Derived from the conceptual model the following hypotheses are formulated: 
H1: There is a positive relationship between IT capability and digital transformation.

H2: e-Competences are positively related to Digital Transformation.

H3: e-Competence positively moderates the relationship between IT Capability and Digital Transformation.

In the following section the research instrument and the process of data collection are described.

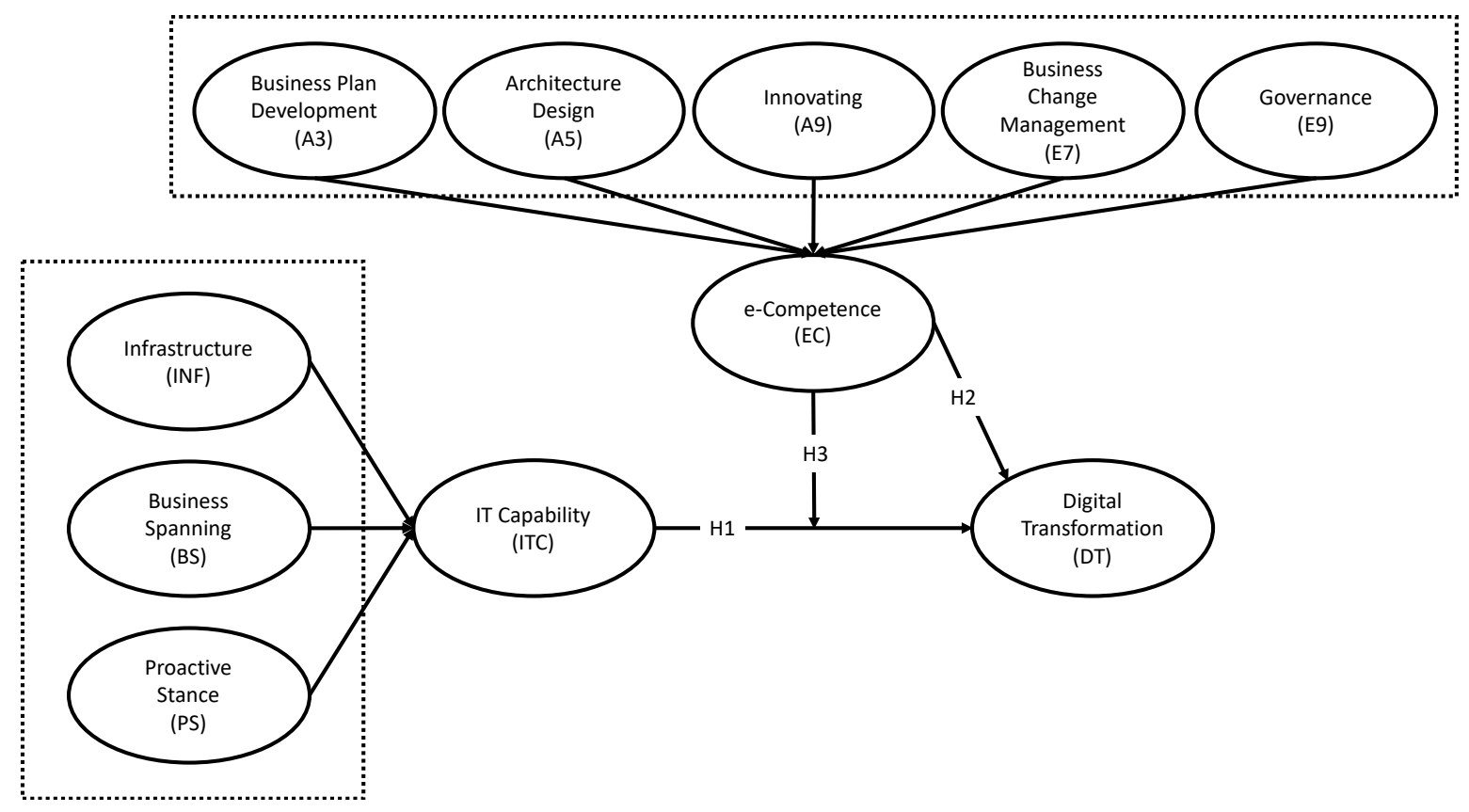

Figure 2. Conceptual Model

\section{METHODOLOGY}

This section discusses the research instrument that is used as well as the data collection process.

\subsection{Measures}

The constructs were measured with multiple indicators coded on a seven-point Likert scale. Digital Transformation is first operationalized by Nwankpa \& Roumani (2016). We adopted their measures for this study. Additionally, we also utilized the measures they used in their study for IT Capability. These are based on prior information systems research (amongst others (Lu \& Ramamurthy, 2011). Finally, we developed a set of questions to measure the e-competences related to digital leadership. The final set of measurement items used to determine scores for each construct and the original source of these measurement items can be received on request to the authors.

\subsection{Sample and Procedure}

Data is collected from June to September of 2018 by students of the Master of Business Studies (Innovation in European Business). The master diploma is awarded and partially delivered by Cork University College (Ireland) in partnership with HU University of Applied Sciences (Netherlands) and ISC Paris School of Management (France). The students surveyed organizations individually. For the purpose of this study, we pooled the data together which resulted in a set that comprised 127 respondents. For the greatest part, namely 118, these are organizations with 250 employees or less, thus SME's. Eight organizations have between 250 and 999 employees and one has more than 1000 employees. The organizations are active in four different industries: Accommodation and food service activities (25.2\%), Information and communication (18.9\%) Financial and insurance activities (19.7\%), Professional, scientific and technical activities (36.2\%). 


\section{RESULTS}

Partial least squares (PLS) is used to test the model as it makes less demand on measurement scales (Gefen, et al., 2000; Hair, et al., 2011) and normal distribution (Chin, 1998). A bootstrap procedure was used to assess the statistical significance of the loadings and of the path coefficients (Ringle, et al., 2015). Bootstrapping is a non-parametric approach for estimation by re-sampling the original data with replacement to get an estimate for each parameter in the PLS model (Chin, 2001). Using the software SmartPLS (Ringle, et al., 2015), the measurement model is examined to assess reliability and validity before testing the structural model and thus test the hypotheses.

\subsection{Measurement Model}

Tables 1, 2, 3 and 4 present the measurement model results. The Cronbach's alpha values are between 0.834 and 0.936 , the composite reliabilities of multi-item scales modeled with reflective indicators are 0.70 or greater, suggesting that the scales have a high level of internal consistency reliability (Hair, et al., 2009). The values of $\rho \mathrm{A}$ are also acceptable as they are above 0.70 (Henseler, et al., 2016). Using the commonly applied criterion of average variance extracted (AVE) being at least 0.50 (Fornell \& Larcker, 1981) the scores also demonstrate sufficient convergent validity of the constructs.

\begin{tabular}{ccccc} 
Table 1. Cronbach's Alpha, Composite Reliabilities and Average Variance Extracted (AVE) \\
\cline { 2 - 5 } $\begin{array}{c}\text { Cronbach's } \\
\text { Alpha }\end{array}$ & $\rho$ A & $\begin{array}{c}\text { Composite } \\
\text { Reliability }\end{array}$ & AVE \\
\hline A3 & 0.867 & 0.872 & 0.919 & 0.790 \\
A5 & 0.887 & 0.888 & 0.930 & 0.815 \\
A9 & 0.834 & 0.840 & 0.923 & 0.858 \\
E7 & 0.894 & 0.894 & 0.934 & 0.825 \\
E9 & 0.904 & 0.905 & 0.954 & 0.913 \\
BS & 0.928 & 0.928 & 0.949 & 0.823 \\
INF & 0.870 & 0.873 & 0.911 & 0.719 \\
PS & 0.936 & 0.938 & 0.955 & 0.840 \\
DT & 0.907 & 0.911 & 0.942 & 0.844 \\
\hline
\end{tabular}

To assess discriminant validity, the latest guidelines are used (Henseler, et al., 2016). Following these guidelines, the Fornell-Larcker criterion (Fornell \& Cha, 1994) is firstly examined. A latent construct should better explain the variance of its own indicator rather than the variance of other latent constructs. Therefore, the square root of each construct's AVE should have a greater value than the correlations with other latent constructs. Table 2 provides the results for our study. The results show insufficient discriminant validity as the correlation of IT Capability with e-Competence is higher than the square root of the AVE of e-Competence. However, to fully examine discriminant validity one should also assess the cross loadings.

Table 2. Correlations (off-Diagonal Elements) and Square Root of the AVEs (Diagonal Elements)

\begin{tabular}{lccc}
\hline & e-Competence & Digital Transformation & IT Capability \\
\hline e-Competence & 0.76 & & \\
Digital Transformation & 0.60 & 0.92 & \\
IT Capability & 0.81 & 0.59 & 0.78 \\
\hline
\end{tabular}

Table 3 shows the cross loadings of the constructs as defined in the conceptual model. Taking a conservative threshold of 0.8 shows discriminant validity of the constructs. However, some loadings do exceed the threshold of 0.7, which is often used as cut-off value (Hair, et al., 2009). 
Table 3. Cross Loadings

\begin{tabular}{|c|c|c|c|c|c|c|c|c|c|}
\hline & A3 & A5 & A9 & E7 & E9 & BS & INF & PS & DT \\
\hline A3_1 & 0.86 & 0.58 & 0.51 & 0.5 & 0.4 & 0.58 & 0.34 & 0.54 & 0.38 \\
\hline A3_2 & 0.91 & 0.63 & 0.60 & 0.61 & 0.54 & 0.66 & 0.45 & 0.65 & 0.39 \\
\hline A3 33 & 0.90 & 0.59 & 0.52 & 0.58 & 0.47 & 0.65 & 0.46 & 0.58 & 0.42 \\
\hline A5_1 & 0.58 & 0.89 & 0.54 & 0.50 & 0.39 & 0.56 & 0.44 & 0.62 & 0.47 \\
\hline A5_2 & 0.59 & 0.92 & 0.59 & 0.51 & 0.44 & 0.62 & 0.47 & 0.67 & 0.47 \\
\hline A5_3 & 0.65 & 0.89 & 0.61 & 0.59 & 0.44 & 0.61 & 0.4 & 0.64 & 0.49 \\
\hline A9_1 & 0.62 & 0.65 & 0.93 & 0.67 & 0.50 & 0.62 & 0.42 & 0.61 & 0.48 \\
\hline A9_2 & 0.51 & 0.53 & 0.92 & 0.65 & 0.50 & 0.57 & 0.39 & 0.53 & 0.48 \\
\hline E7_1 & 0.59 & 0.49 & 0.67 & 0.90 & 0.57 & 0.57 & 0.41 & 0.52 & 0.51 \\
\hline E7_2 & 0.60 & 0.59 & 0.66 & 0.92 & 0.46 & 0.58 & 0.41 & 0.62 & 0.55 \\
\hline E7_3 & 0.53 & 0.53 & 0.62 & 0.90 & 0.54 & 0.54 & 0.44 & 0.56 & 0.46 \\
\hline E9_1 & 0.50 & 0.40 & 0.49 & 0.58 & 0.95 & 0.5 & 0.48 & 0.45 & 0.41 \\
\hline E9_2 & 0.52 & 0.50 & 0.54 & 0.52 & 0.96 & 0.54 & 0.44 & 0.46 & 0.39 \\
\hline BS_1 & 0.66 & 0.59 & 0.55 & 0.57 & 0.51 & 0.88 & 0.57 & 0.75 & 0.56 \\
\hline BS_2 & 0.70 & 0.62 & 0.60 & 0.53 & 0.48 & 0.93 & 0.48 & 0.66 & 0.49 \\
\hline BS_3 & 0.60 & 0.61 & 0.60 & 0.63 & 0.51 & 0.90 & 0.55 & 0.64 & 0.38 \\
\hline BS_4 & 0.62 & 0.57 & 0.59 & 0.52 & 0.47 & 0.92 & 0.53 & 0.69 & 0.45 \\
\hline INF_1 & 0.41 & 0.41 & 0.43 & 0.39 & 0.42 & 0.51 & 0.87 & 0.46 & 0.46 \\
\hline INF_2 & 0.39 & 0.40 & 0.42 & 0.47 & 0.43 & 0.46 & 0.84 & 0.52 & 0.34 \\
\hline INF_3 & 0.47 & 0.44 & 0.40 & 0.41 & 0.40 & 0.57 & 0.84 & 0.57 & 0.46 \\
\hline INF_4 & 0.32 & 0.37 & 0.22 & 0.28 & 0.37 & 0.45 & 0.83 & 0.39 & 0.36 \\
\hline PS_1 & 0.68 & 0.70 & 0.55 & 0.51 & 0.50 & 0.66 & 0.50 & 0.89 & 0.47 \\
\hline PS_2 & 0.64 & 0.65 & 0.58 & 0.53 & 0.41 & 0.73 & 0.53 & 0.94 & 0.49 \\
\hline PS_3 & 0.51 & 0.62 & 0.53 & 0.58 & 0.41 & 0.65 & 0.50 & 0.92 & 0.47 \\
\hline PS_4 & 0.61 & 0.64 & 0.62 & 0.66 & 0.43 & 0.73 & 0.57 & 0.92 & 0.59 \\
\hline DT_1 & 0.43 & 0.46 & 0.49 & 0.48 & 0.37 & 0.52 & 0.38 & 0.48 & 0.91 \\
\hline DT_2 & 0.44 & 0.52 & 0.52 & 0.56 & 0.41 & 0.46 & 0.50 & 0.53 & 0.95 \\
\hline DT_3 & 0.36 & 0.49 & 0.41 & 0.50 & 0.37 & 0.45 & 0.43 & 0.50 & 0.89 \\
\hline
\end{tabular}

Additionally, following the latest guidelines, the heterotrait-monotrait ratio of correlations (HTMT) is also used to assess discriminant validity. Henseler Ringle and Sarstedt (2015) argued a strong case of using this approach. In order to clearly discriminate between two factors, the HTMT should be smaller than 0.90 (Henseler, et al., 2016). As Table 4 shows, all correlations comply to that criterion. Hence, discriminant validity is demonstrated by the heterotrait-monotrait ratio. 
Table 4. Heterotrait-monotrait Ratio of Correlations (HTMT)

\begin{tabular}{lllllllll}
\hline & A3 & A5 & A9 & DT & E7 & E9 & BS & INF \\
\hline A5 & 0.77 & & & & & & & \\
A9 & 0.72 & 0.74 & & & & & & \\
DT & 0.50 & 0.59 & 0.59 & & & & & \\
E7 & 0.72 & 0.66 & 0.83 & 0.62 & & & & \\
E9 & 0.60 & 0.52 & 0.62 & 0.46 & 0.64 & & & \\
BS & 0.79 & 0.73 & 0.73 & 0.56 & 0.68 & 0.59 & & \\
INF & 0.54 & 0.55 & 0.51 & 0.53 & 0.52 & 0.54 & 0.65 & 0.63 \\
PS & 0.74 & 0.78 & 0.70 & 0.59 & 0.68 & 0.52 & 0.81 & \\
\hline
\end{tabular}

In sum, the data suffices for reliability and convergent validity, but displays mixed scores with regard to discriminant validity. For the purpose of this study, we continued with this data, but future research is needed to investigate the rationale behind this.

To test for multicollinearity, the variance inflation factors (VIFs) were computed (Kock, 2015). The values ranged from 1.97 and 4.89. Although some are a little bit high, they are found to be less than the conservative threshold of 5 . Hence, this suggests that multicollinearity was not a major issue in the study.

\subsection{Structural Model and Hypotheses Testing}

In PLS analysis, examining the structural paths and the R-square scores of the endogenous variables, assess the explanatory power of the structural model. A bootstrapping procedure with 127 cases and 1000 subsamples was used to test the significance of all paths in the research model (Hair, et al., 2011). The results of the structural model are shown in Figure. The results suggest that the model is capable of explaining $40 \%$ of the variance of digital transformation. In support of hypothesis 1, IT Capability has a significant positive impact on digital transformation $(\beta=0.296, \mathrm{p}<0.001)$. Similarly, in support of hypothesis 2, e-Competence has a significant positive relationship with digital transformation $(\beta=0.342, p<0.001)$. Hypothesis 3 states that digital transformation has a positive moderating effect on the relation between IT Capability and Digital Transformation. This hypothesis was not supported $(\beta=-0.047, \mathrm{p}=0.248)$.

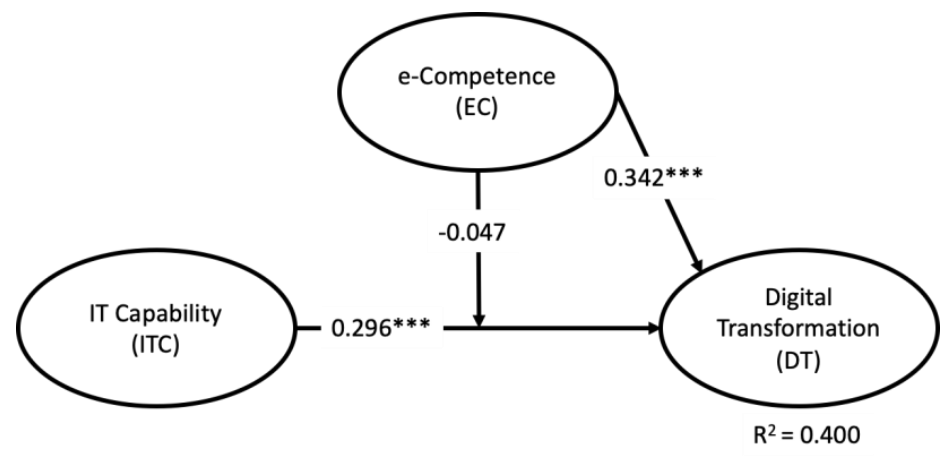

Figure 3. Hypothesis testing $(* * * \mathrm{p}<0.001)$

\section{DISCUSSION AND CONCLUSIONS}

This study examined the mediating role of digital leadership in the relationship between IT capability and digital transformation, for this we introduced the concept of e-Competences. A theoretical framework explaining the effect of digital leadership was tested using a survey of 127 respondents from firms across 
Western Europe. Consistent with our proposed model, this research finds that both IT capability and e-Competences positively influences digital transformation. The e-Competences related to the Digital Transformation Leader role do not moderate the relation between IT capabilities and digital transformation.

\subsection{Implications for Theory and Practice}

This study offers several theoretical implications. First, our study confirms prior research (e.g. (Nwankpa \& Roumani, 2016) that found a significant positive relation between IT capabilities and digital transformation. Secondly, although prior studies have shown the influence of IT capability on digital transformation, less is known about the role of e-competences. To the best of our knowledge, this is the first study that empirically scrutinized the concept of e-competences in the role of digitally transforming businesses. The results of a significant relation between e-competences and digital transformation contributes to the theoretical development of determinants if this dependent concept.

Our research has also implications for professionals, e.g. managers. Specifically, the study will be of practical importance to managers and executives who are initiating plans to integrate digital technologies with their business processes. Practitioners should recognize that investments for digital transformation should be directed not only to IT capabilities, but also to e-competences. Enhancing personnel's leadership qualities as formulated in the European e-Competence Framework. More specifically, managers should pay attention to competences of business plan development, architecture design, innovating, business change management, and IS governance.

\subsection{Limitations and Future Research}

As any empirical study, this work has several limitations which should be recognized. First, our model comprised limited key constructs in relation to digital transformation. Other factors like financial resources or the culture of the organization potential influence the digital transformation. Future research could examine a more comprehensive model. Secondly, although the we utilized prior research for the operationalization of digital transformation, it is mainly focused on the use of technology. Anecdotal research however argues a more multidimensional approach of this concept. Westerman, Bonnet and McAfee (2014a) postulate three major building blocks of digital transformation, i.e. customer experience, operational processes, business models. This field of research should benefit from a validated operationalization of this construct for future references. Third, one must stipulate the representativeness of the sample. The limited number of respondents is not only skewed to SMEs, but also not well distributed over sectors. Hence, the conclusions must be interpreted with caution. Future research will extend the dataset with subjects in order to increase the reliability and validity of our study.

Despite these limitations we think this research contributes to the discussion of digital transformation and the factors that influence this, often radical, change that organizations are faced with.

\section{REFERENCES}

Anand, J., Oriani, R. \& Vassolo, R. S., 2010. Alliance activity as a dynamic capability in the face of a discontinuous technological change. Organization Science, 21(6), pp. 1213-1232.

Avolio, B. J., Sosik, J. J., Kahai, S. S. \& Baker, B., 2014. E-leadership: Re-examining transformations in leadership source and transmission. The Leadership Quarterly, 25(1), pp. 105-131.

Bharadwaj, A., 2000. A Resource-Based Perspective on Information Technology Capability and Firm Performance: An Empirical Investigation. MIS Quarterly, 24(1), pp. 169-196.

CEN, 2016. The European Committee for Standardization, standard EN 16234- 1:2016, Available from: https://standards.cen.eu.

Chen, J. S. \& Tsou, H. T., 2012. Performance effects of IT capability, service process innovation, and the mediating role of customer service. Journal of Engineering and Technology Management, 29(1), pp. 71-94.

Chin, W., 1998. The partial least squares approach to structural equation modeling. In: G. Marcoulides, ed. Modern Methods for Business Research. Mahwah, N.J: Lawrence Erlbaum Associates, p. 1295-1336.

Chin, W. W., 2001. PLS-Graph User's Guide. Houston: C.T. Bauer College of Business, University of Houston. 
Coombs, J. E. \& Bierly III, P. E., 2006. Measuring technological capability and performance. R\&D Management, 36(4), pp. 421-438.

CWA 16458-1, 2018. CEN, the European Committee for Standardization. European ICT professionals role profiles 1-4. CWA 16458. Retrieved from https://standards.cen.eu/dyn/www/f?p=CENWEB:84:::NO:::

Drnevich, P. L. \& Croson, D. C., 2013. Information technology and business-level strategy: Toward an integrated theoretical perspective. MIS Quarterly, 37(2), pp. 483-509.

e-CF, 2014. e-CF, the European e-Competence Framework, version 3.0, Available from: http://www.ecompetences.eu.

Fornell, C. \& Cha, J., 1994. Partial least squares. Advanced Methods of Marketing Research, Volume 407, p. 52-78.

Fornell, C. \& Larcker, D., 1981. Evaluating structural equation models with unobservable measurement error. Journal of Marketing Research, 18(1), p. 39-50.

Gefen, D., Straub, D. \& Boudreau, M., 2000. Structural equation modeling techniques and regression: Guidelines for research practice. Communications of AIS, 4(7), pp. 1-77.

Hair, J. et al., 2009. Multivariate data analysis. 7th ed. Englewood Cliffs, NJ: Prentice Hall.

Hair, J., Ringle, C. \& Sarstedt, M., 2011. PLS-SEM: Indeed a Silver Bullet. Journal of Marketing Theory and Practice, 19(2), pp. 139-152.

Henriette, E., Feki, M. \& Boughzala, I., 2015. The Shape of Digital Transformation: A Systematic Literature Review. In: Proceedings of the Mediterranean Conference on Information Systems. Samos: Greence.

Henseler, J., Hubona, G. \& Ray, P., 2016. Using PLS path modeling in new technology research: updated guidelines. Industrial Management \& Data Systems, 116(1), pp. 2-20.

Henseler, J., Ringle, C. M. \& Sarstedt, M., 2015. A New Criterion for Assessing Discriminant Validity in Variance-based Structural Equation Modeling. Journal of the Academy of Marketing Science, 43(1), pp. 115-135.

Hüsing, T., Korte, W.B., Fonstad, N., Lanvin, B., Cattaneo, G., Kolding, M., Lifonti, R. \& Van Welsum, D., 2013. eLeadership: e-Skills for Competitiveness and Innovation - Vision, Roadmap and Foresight Scenarios, Final Report, Empirica - Gesellschaft für Kommunikations- und Technologieforschung mbH, Bonn.

Ismail, M.H., Khater, M., \& Zaki, M., 2017. Digital Business Transformation and Strategy: What Do We Know So Far?, Cambridge Service Alliance, Working Paper, 2017.

Kane, G. C. P. D., Phillips, A. N., Kiron, D. \& Buckley, N., 2015. Strategy, not technology, drives digital transformation. MIT Sloan Management Review and Deloitte University Press, pp. 1-25.

Kock, N., 2015. Common method bias in PLS-SEM: A full collinearity assessment approach. International Journal of e-Collaboration, 11(4), pp. 1-10.

Kutzner, K., Schoormann, T., \& Knackstedt, R., 2018. Digital Transformation in Information Systems Research: A Taxonomy-Based Approach to Structure the Field. In: Proceedings of the 26th European Conference on Information Systems (ECIS), Portsmouth, UK

Libert, B., Beck, M., \& Wind, Y., 2016. "7 Questions to ask before your next digital transformation," Harvard Business Review, July 2016

Lu, Y. \& Ramamurthy, K., 2011. Understanding the link between information technology capability and organizational agility: An empirical examination. MIS Quarterly, 35(4), pp. 931-954.

Matt, C., Hess, T. \& Benlian, A., 2015. Digital transformation strategies. Business \& Information Systems Engineering 57 (5), pp. 339-343.

Mithas, S., Ramasubbu, N. \& Sambamurthy, V., 2011. How information management capability influences firm performance. MIS Quarterly, 35(1), pp. 237-256.

Nwankpa, J. \& Roumani, Y., 2016. IT Capability and Digital Transformation: A Firm Performance Perspective. Dublin, s.n.

Plessius, H. \& Ravesteyn, P., 2016. Mapping the European e-Competence Framework on the domain of Information Technology: a comparative study. Bled, Slovenia, 29th Bled eConference: Digital Economy.

Prentice, W. C. H., 2004. Understanding leadership. Harvard Business Review, 82(1), pp. 102-109.

Ringle, C. M., Wende, S. \& Becker, J.-M., 2015. SmartPLS 3. Boenningstedt: SmartPLS GmbH.

Robinson, S. L. et al., 2015. New curricula for e-leadership skills. Guidelines and quality labels for new curricula for e-Leadership skills in Europe, Available from: http://eskillsguide.eu/documents/.

Sheninger, E., 2014. Digital leadership: Changing paradigms for changing times. s.1.:Corwin Press.

Westerman, G., Bonnet, D. \& McAfee, A., 2014a. The Nine Elements of Digital Transformation. MIT Sloan Management Review.

Westerman, G., Bonnet, D. \& McAfee, A., 2014b. Leading digital: Turning technology into business transformation.. s.l.:Harvard Business Press. 